

\title{
Grau de adoção dos Princípios do Lean Construction em dois canteiros de obras localizados no munícipio de Belém
}

\author{
DEGREE OF ADOPTION OF LEAN CONSTRUCTION PRINCIPLES IN TWO \\ CONSTRUCTION SITES LOCATED IN BELÉM MUNICIPALITY
}

1 Mestre em Engenharia Civil pela Universidade Federal do Pará Universidade do Estado do Pará - UEPA Belém, Pará - Brasil. ricardows@ufpa.br
Resumo: O LC destaca-se por proporcionar vantagem competitiva às empresas na forma de redução de prazos, custos, desperdícios e aumento da qualidade. Nesse contexto, o objetivo deste trabalho é analisar o grau de adoção dos princípios do LC por meio de um estudo de casos múltiplos em dois canteiros de obras localizados no munícipio de Belém, região norte do Brasil, mediante a verificação das práticas lean inerentes aos onze princípios do LC, e, posteriormente, fazer uma comparação. Na metodologia, foram aplicadas entrevistas, observações diretas e questionários a fim de realizar essa análise. Os resultados mostraram baixo conhecimento sobre as práticas do LC e, sobretudo, dos princípios do LC, indicando a necessidade de as construtoras atualizarem-se e implementarem essas práticas em seus canteiros. A contribuição científica deste estudo reside na importância de conhecer o grau atual de LC desses canteiros nessa localidade, e subsidiar amplas discussões a respeito desse tema.

Palavras-Chave: Lean construction. Práticas do lean construction. Princípios do Lean Construction.

Abstract: LC stands out for providing companies with a competitive advantage in the form of reduced deadlines, costs, waste and increased quality. In this context, the objective of this work is to analyze the degree of adoption of the principles of the LC through a study of multiple cases in two construction sites located in the municipality of Belém, northern region of Brazil, through the verification of the lean practices inherent to the eleven LC principles, and then make a comparison. Interviews, direct observations and questionnaires were applied to make this analysis. The results showed low knowledge about the practices of the LC and, above all, the principles of the $\mathrm{LC}$, indicating the need for the construction companies to update themselves and implement these practices in their construction sites. The scientific contribution of this study resides in the importance of knowing the current degree of LC of these beds in this location, and to support broad discussions on this topic.

Keywords: Lean Construction. Lean construction practices. Lean Construction Principles. 


\section{Introdução}

O setor da construção civil é um importante segmento da indústria brasileira, e é considerado um indicativo de crescimento econômico e social (Fernandez, 2012). Apesar do período de instabilidade devido à crise econômica ocorrida no Brasil entre 2014 e 2019, segundo a Câmera Brasileira da Indústria da Construção [CBIC], o setor inicia o ano de 2020 com perspectiva de expansão em cenários de juros baixos e inflação controlada, devendo progredir 3\% este ano e gerar 150 mil postos de trabalho formais até dezembro.

Diante desse contexto, e considerando o aumento da competitividade no mercado entre as empresas, o elevado nível de exigência dos clientes, a maior preocupação com o meio ambiente e a busca por maior lucratividade dos investidores são resultados da globalização. Uma das alternativas que as empresas têm buscado é a adoção das práticas do Lean Construction $[L C]$, uma vez que possibilitam a otimização de processos (Fabro et al., 2020), redução das perdas e desperdícios (Pheng, Shang, \& Peter, 2016; Salgin, Arroyo \& Ballard, 2016), ganhos econômicos (Ballard et al., 2008; Ballard, 2009), ganhos com a sustentabilidade (Saggin et al.,2015; Almeida \& Picchi, 2018), e ganhos ambientais (Golzapoor \& Gonzáles, 2013; Ghosh et al., 2014).

Haja vista a necessidade de discutir, amadurecer, consolidar e difundir tais práticas, vários autores passaram a oferecer contribuições no sentido de demonstrar os benefícios do LC. Pérez et al. 2016, por exemplo, estudaram as perdas ocasionadas durante os processos de transporte nas atividades da construção civil em dois empreendimentos residenciais no Brasil, sugerindo a aplicação de princípios Lean como alternativa para combater tais perdas.

Shang e Pheng (2014), por outro lado, desenvolveram um estudo sobre as práticas do LC na indústria da construção na China, em relação às principais barreiras de implementação de tais práticas nas organizações, demonstrando por meio dos seus resultados que essas barreiras consistem em: falta de uma filosofia lean de longo prazo, conhecimento insuficiente de lean, ausência de uma cultura enxuta, habilidades insuficientes de gerenciamento, entre outras.

Dessa forma, o presente trabalho visa analisar o grau de adoção dos princípios do Lean Construction em dois canteiros de obras localizados no município de Belém, região norte do Brasil, por meio da verificação das práticas Lean inerentes aos onze princípios do LC criados por Koskela (1992), e, posteriormente fazer uma comparação por meio de aplicação de entrevistas, observações diretas e questionários, de modo a responder o seguinte questionamento: qual o percentual de desempenho de aplicação dos princípios do $L C$ nesses canteiros? Essa questão visa a obtenção de uma noção geral do desempenho e determinar o grau de adoção de tais princípios.

A contribuição científica deste estudo reside na importância de conhecer o grau atual de $L C$ desses canteiros nessa localidade, e servir como subsídio para ampliar as discussões acerca desse tema. 


\section{Referencial teórico}

\subsection{Lean Construction (Construção Enxuta)}

As ideias de $L C$ surgiram no Japão nos anos 50, sendo o Sistema de Produção da Toyota no Japão a aplicação mais notável. Teve como marco principal a publicação do relatório técnico $n^{\circ} 72-$ "Application of the new philosofy in the Construction industry", por Koskela (1992), publicado pelo Center for Integrated Facility Engineering [CIFE] ligada à Universidade de Stanford nos Estados Unidos da América - EUA, onde o autor definiu como uma filosofia de produção enxuta orientada e adaptada à indústria da construção civil e suas peculiaridades, e também uma maneira de projetar sistemas de produção para minimizar desperdício de materiais, tempo e esforço, a fim de gerar a quantidade máxima possível de valor.

Nesse relatório foi também apresentado os onze princípios heurísticos para projeto e melhoria de fluxo de processo, considerados a base do $L C$. Segundo o autor, para a obtenção dos resultados esperados, esses princípios devem ser aplicados de forma integrada na gestão dos processos.

Os onze princípios do $L C$ de acordo com esse autor são: (1) Reduzir as atividades que não agregam valor; (2) Aumentar o valor para o cliente; (3) Reduzir a variabilidade; (4) Reduzir os tempos de ciclo; (5) Simplificação dos processos; (6) Aumentar a flexibilidade das saídas; (7) Aumentar a transparência dos processos; (8) Focar no planejamento e controle do processo completo; (9) Melhoria contínua dos processos; (10) Equilibrar melhorias de fluxo com melhoria na conversão; (11) Benchmarking.

Carvalho (2013) apresentou uma compilação de diversas práticas lean relacionadas aos onzes princípios de Koskela (1992), conforme mostrado no quadro 1, em anexo e no apêndice deste artigo que mostra algumas dessas práticas.

\subsection{Ferramentas do Lean Construction}

Existem várias ferramentas que auxiliam na implementação do $L C$. No quadro 2, constam exemplos de ferramentas citadas na literatura científica: 


\section{Quadro 2}

\section{Exemplos de Ferramentas Lean Construction}

\begin{tabular}{|c|c|}
\hline Ferramentas Lean Construction & Autores \\
\hline Planejamento & $\begin{array}{l}\text { (Andrade \& Arrieta, 2011; Campos \& Azevedo, } 2016 \text { Vargas \& Formoso, } \\
\text { 2019; Fabro et al., 2020) }\end{array}$ \\
\hline $\begin{array}{l}\text { Planejamento de Longo Prazo ou } \\
\text { Estratégico via LOB e PERT/COM }\end{array}$ & $\begin{array}{l}\text { (Andrade \& Arrieta, 2011; Campos \& Azevedo, } 2016 \text { Vargas \& Formoso, } \\
\text { 2019; Fabro et al., 2020) }\end{array}$ \\
\hline $\begin{array}{l}\text { Planejamento de Médio Prazo, } \\
\text { Tático ou Lookahead Planning }\end{array}$ & $\begin{array}{l}\text { (Andrade \& Arrieta, 2011; Aziz \& Hafez, 2013; ; Campos \& Azevedo, } 2016 \\
\text { Vargas \& Formoso, 2019; Angelim et al., 2019; Fabro et al., 2020) }\end{array}$ \\
\hline $\begin{array}{l}\text { Planejamento de Curto Prazo ou } \\
\text { Operacional, Last Planner }\end{array}$ & $\begin{array}{l}\text { (Andrade \& Arrieta, 2011; Bulhões \& Picchi, 2011; Aziz \& Hafez, 2013; } \\
\text { Pereira \& Cachadinha, 2011; Campos \& Azevedo, 2016; Vargas \& } \\
\text { Formoso, 2019; Fabro et al., 2020) }\end{array}$ \\
\hline $\begin{array}{l}\text { 5S (Seiri, Seiton, Seisou, Seiketsu e } \\
\text { Shitsuke) }\end{array}$ & $\begin{array}{l}\text { (Pereira \& Cachadinha, 2011; Salem et al., 2014; Maradzano, } \\
\text { Dondofema, \& Matope, 2015; Almeida \& Picchi, 2018) }\end{array}$ \\
\hline $\begin{array}{l}\text { Gerenciamento Visual, Andon e } \\
\text { Transparência }\end{array}$ & (Pereira \& Cachadinha, 2011; Salem et al., 2014) \\
\hline Poka-Yoke (à prova de erros) & (Koskela, 1992; Tommelein, 2008) \\
\hline Mapeamento do Fluxo de Valor & $\begin{array}{l}\text { (Bulhões \& Picchi, 2011; Pereira \& Cachadinha, 2011; Filho et al., 2017; } \\
\text { Euphrosino et al., 2019) }\end{array}$ \\
\hline Kanban & (Aziz \& Hafez, 2013) \\
\hline
\end{tabular}

Fonte: Autor (2019).

\subsection{Certificação PBQP- H Nível A}

O Programa Brasileiro de Qualidade e Produtividade no Habitat [PBQP - H], do Ministério das Cidades, possui um Sistema de Avaliação da Conformidade dos Serviços e Obras [SiAC] que avalia vários benefícios para as empresas conforme demonstrado no website http://pbqp-h.cidades.gov.br, os quais englobam algumas das práticas lean apresentadas no quadro 2, como: moradia e infraestrutura de melhor qualidade, redução de custo, aumento da produtividade, qualificação dos recursos humanos, modernização tecnológica e gerencial e satisfação dos clientes, e que contribuem para redução de perdas.

Segundo o Ministério das Cidades, O PBQP-H integra-se à Secretaria Nacional de Habitação e é um instrumento do Governo Federal que visa organizar o setor da construção civil em torno de duas questões principais: a melhoria da qualidade do habitat e a modernização produtiva. Além disso, de acordo com o Ministério, o SiAC avalia a conformidade do sistema de gestão da qualidade das empresas, considerando as características específicas do setor da construção civil, baseando-se na série de normas International Organization for Standardization [ISO] 9000, propondo a evolução dos patamares de qualidade da construção civil em quatro níveis, que vai do nível $D$ até o $A$.

\section{Procedimentos metodológicos}

Nesta seção serão apresentados os aspectos metodológicos deste estudo, abordando o método de pesquisa e as etapas seguidas ao longo do desenvolvimento deste trabalho. 


\subsection{Método da pesquisa}

As etapas seguidas nesse estudo de casos múltiplos foram elaboradas a partir do método sugerido por Yin (2010, p.82), e, constituiu-se de três etapas: definição do projeto; coleta de dados; e análise de dados. Essa abordagem é ilustrada na figura 1.

\section{Figura 1}

Etapas da pesquisa

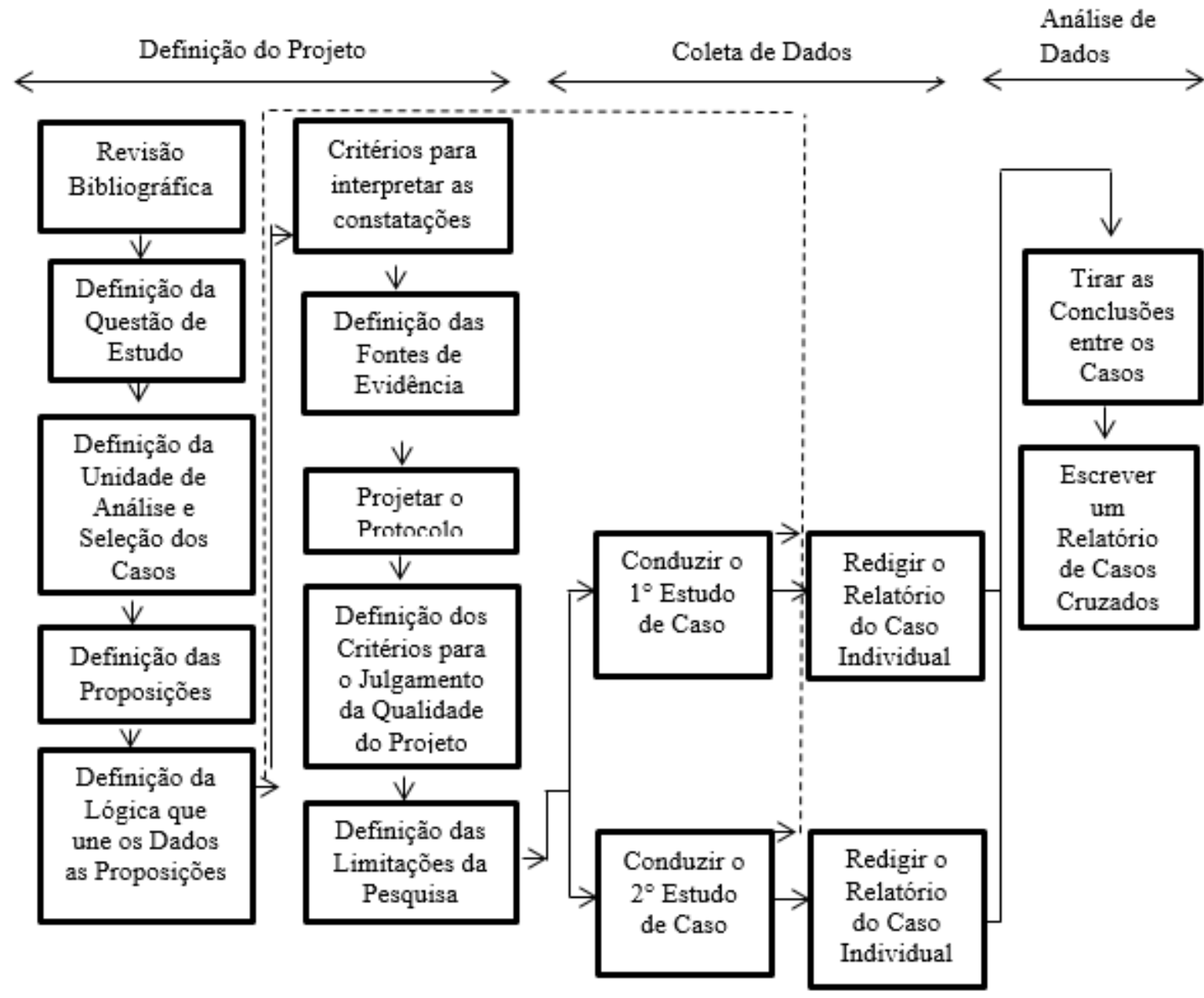

Fonte: Adaptado de Yin (2010)

\subsection{Definição do projeto}

$\mathrm{Na}$ fase inicial desta pesquisa, foi feita uma revisão bibliográfica a partir de livros e artigos científicos relacionados aos princípios do $L C$. Foi feita uma pesquisa de artigos nas bases Compendex, Scopus, Web of Science, Science Direct, SciELO, Emerald Insight e International Group of Lean Construction [IGLC], a partir da string de busca (lean construction OR lean Construction principles), para levantar o maior número possível de artigos relacionados à implementação dos princípios do LC. 
A partir da revisão bibliográfica, foi elaborada a questão que é a principal problematização desta pesquisa: "Qual o grau de adoção dos princípios do LC em dois canteiros de obras localizados no munícipio de Belém?" E, em seguida, definida a unidade de análise do presente estudo que consiste em duas obras de construção vertical localizadas no município de Belém. Porém, em razão da ausência de um selo ou certificação relacionado à utilização das práticas do $L C$, foi adotado como critério para seleção dos casos as certificações de qualidade ISO 9001:2008 e PBQP-H nível A.

Dessa forma, para responder a questão proposta na pesquisa, foi realizado um estudo de caso múltiplo em um canteiro de obra de uma empresa construtora que possui as certificações de qualidade ISO 9001:2008 e PBQP-H nível A, na condição de que essa adota as práticas do LC, o qual foi chamado de canteiro de obra A, e em uma obra de uma empresa que não possui nenhuma certificação, considerando que essa não adota tais práticas em suas obras, chamada de canteiro de obra B, com o intuito de compará-las quanto ao grau de adoção dos princípios do LC. É importante ressaltar também que para a seleção dos casos foram consideradas empresas construtoras que têm como atividade principal a construção de edificações verticais (públicas, residenciais ou comerciais).

A construtora responsável pelo canteiro de obra A atua no mercado paraense com sede na cidade de Belém, desde 1979. O foco maior da empresa é na construção de edifícios públicos, residenciais, comerciais, hospitais e shoppings. A obra em estudo teve início em abril de 2016, e tem como previsão de conclusão março de 2020, sendo considerada um tipo de edificação pública e cuja estrutura é constituída de dois blocos.

A construtora do canteiro de obra B atua no mercado paraense também com sede na cidade de Belém, há exatos 32 anos, com duas frentes: construção de edificações (residenciais e comerciais), com a inauguração de mais de 15 projetos de edificação na cidade de Belém. A obra em estudo está localizada em uma região nobre da cidade de Belém, e é considerada um empreendimento de alto padrão, composta de 1 uma torre e 29 pavimentos. A data de início da obra foi em agosto de 2015 e a previsão de término é em dezembro de 2020.

Foram definidos, com base no modelo de determinação do grau de adoção dos princípios do $L C$ proposto por Lucato et al. (2006) conforme citado em Carvalho (2008), alguns questionamentos considerados suficientes para interpretação dos achados e posterior comparação após os dados serem coletados, como: Quais são os motivos existentes pelos quais as práticas lean relacionadas a determinado princípio não são aplicadas? As práticas lean adotadas são aplicadas de forma planejada ou inconsciente? Se determinado princípio é aplicado, há oportunidades de desenvolvimento? Quais são as melhorias advindas da aplicação das práticas relacionadas a determinado princípio? Estas questões foram de suma importância para analisar de fato o grau de adoção dos princípios do $L C$ nos dois canteiros de obras em estudo. 
Foram utilizadas três técnicas de coleta de dados: entrevistas, questionários e observações diretas, com o intuito de conhecer as práticas que são e não são adotadas nos canteiros, as dificuldades existentes, procedimentos, etc. É importante ressaltar que o questionário respondido que consta no apêndice deste artigo, foi elaborado com base na compilação de práticas lean apresentadas por Carvalho (2013) e relacionadas aos onze princípios de Koskela (1992) citadas no referencial teórico, sendo fundamental para analisar o grau de aplicação dos princípios do LC.

Além disso, todos os procedimentos e regras gerais seguidas na fase de coleta de dados foram definidos no protocolo do estudo de caso, que é um documento importante de acordo com Yin (2010), cuja finalidade é aumentar a confiabilidade da pesquisa e orientar o investigador na realização da coleta de dados.

O questionário trouxe perguntas relacionadas à aplicação das práticas do $L C$ inerentes a cada princípio proposto por Koskela (1992), com quatro possibilidades de resposta, distribuídas entre zero a três, sendo o zero quando o princípio que não está aplicado e três quando o princípio está efetivamente aplicado com melhorias visíveis. O número de perguntas por princípio e o somatório máximo das respostas pode ser visualizado na tabela 1 :

\section{Tabela 1}

Quantidade de perguntas por princípio e somatório máximo das respostas

\begin{tabular}{llll}
\multicolumn{1}{c}{ Princípio } & N de Perguntas & \multicolumn{1}{c}{$\begin{array}{c}\text { Somatório máximo das } \\
\text { respostas }\end{array}$} \\
\hline 1 Redução de atividades que não agregam valor & 8 & 24 \\
2 Aumentar o valor para o cliente & 6 & 18 \\
3 & Reduzir a variabilidade & 3 & 9 \\
4 & Reduzir os tempos de ciclo & 7 & 21 \\
5 & Simplificação dos processos & 3 & 9 \\
6 & Aumentar a flexibilidade das saídas & 4 & 12 \\
7 Aumentar a transparência dos processos & 3 & 9 \\
8 Focar no planejamento e controle do processo & 8 & 24 \\
9 completo & Melhoria contínua dos processos & 7 & 21 \\
10 & Equilibrar melhorias de fluxo com melhoria na & 2 & 6 \\
conversão & Benchmarking & 1 & 3 \\
TOTAL & 52 & 156
\end{tabular}

Fonte: Autor (2019).

Em cada questionário aplicado foi feito o somatório das respostas por princípio e dividiu-se o valor obtido pelo somatório máximo daquele princípio, visando obter um percentual de desempenho, para cada um dos onze princípios. Lucato et al. (2006) como citados em Carvalho (2008) determinaram 
quatro intervalos para classificar o grau de adoção de cada princípio dentro de uma empresa, que foi adaptado da seguinte forma para os canteiros de obras em estudo:

0\% a 25\% - o princípio não está presente;

25\% a 50\% - há incidência de aplicação do princípio, porém de maneira inconsciente;

50\% a 75\% - o princípio está aplicado, porém evidencia oportunidades de desenvolvimento;

$75 \%$ a 100\% - o princípio está totalmente presente e resulta em melhorias para o canteiro de obras.

O percentual de desempenho global do canteiro é calculado pela soma das respostas de todos os princípios, obtidos no questionário, dividido pelo somatório máximo de todas as respostas. Dessa forma, pode-se obter uma noção geral do desempenho quanto à aplicação das práticas do $L C$, e classificá-los de acordo com a tabela 2, que determina o grau de adoção de tais princípios nos canteiros.

\section{Tabela 2}

Níveis para a classificação da empresa por percentual de desempenho global

\begin{tabular}{|c|c|c|c|}
\hline Nível & Subnível & Percentual & Característica \\
\hline A & $\begin{array}{l}\text { AAA } \\
\text { AA } \\
\text { A }\end{array}$ & $\begin{array}{l}95 \% \text { a } 100 \% \\
90 \% \text { a } 94 \% \\
85 \% \text { a } 89 \%\end{array}$ & Busca pela perfeição na construção enxuta \\
\hline B & $\begin{array}{l}\text { BBB } \\
\text { BB } \\
B\end{array}$ & $\begin{array}{l}80 \% \text { a } 84 \% \\
75 \% \text { a } 79 \% \\
70 \% \text { a } 74 \%\end{array}$ & Consciência e aprendizado enxuto \\
\hline C & $\begin{array}{l}\mathrm{CCC} \\
\mathrm{CC} \\
\mathrm{C}\end{array}$ & $\begin{array}{l}65 \% \text { a } 69 \% \\
60 \% \text { a } 64 \% \\
55 \% \text { a } 59 \%\end{array}$ & Foco em qualidade, mas baixo ou nenhum conhecimento nas práticas do $L C$ \\
\hline$D$ & $\begin{array}{l}\text { DDD } \\
\text { DD } \\
\text { D }\end{array}$ & $\begin{array}{l}50 \% \text { a } 54 \% \\
45 \% \text { a } 49 \% \\
0 \% \text { a } 44 \%\end{array}$ & Baixo foco em melhorias. Conhecimento nulo sobre as práticas do $L C$ \\
\hline
\end{tabular}

Fonte: Lucato et al. (2006) como citado em Carvalho (2008).

Conforme Yin (2010) foram definidos três testes para avaliar a qualidade dessa pesquisa: validade do constructo, validade externa e confiabilidade. Para aumentar a validade do constructo, por exemplo, foi utilizada a tática de múltiplas fontes de evidência visando incentivar linhas convergentes de investigação, enquanto para o teste de validade externa foi utilizada a tática da replicação por meio do estudo de caso múltiplo para a obtenção da generalização analítica.

Foram elencadas algumas limitações da pesquisa para o desenvolvimento deste estudo de caso múltiplo, como: a dificuldade de conseguir empresas que permitissem a aplicação desse estudo em seus 
canteiros de obra; a restrição ao acesso às documentações e arquivos da empresa e a dificuldade de entrevistar os responsáveis por gerenciar as obras em estudo.

\subsection{Coleta de dados}

$\mathrm{Na}$ fase de coleta de dados, os estudos foram preparados, conduzidos e analisados, e houve subdivisão em dois momentos: condução dos estudos de casos e elaboração do relatório de caso individual. Todos os procedimentos de campo para a condução desses estudos constam no protocolo do estudo de caso, e inclui o plano de coleta de dados que ocorreu em três etapas e a preparação necessária para realização das visitas.

Na primeira etapa do plano de coleta de dados, foram agendadas entrevistas com os executivos das empresas a fim de obter informações sobre a empresa em estudo, tais como: tempo de atuação, segmento, histórico/evolução da empresa, número de funcionários, metros quadrados construídos por ano, número de empreendimentos lançados, número de empreendimentos em construção e as certificações e premiações obtidas, conforme protocolo do estudo de caso.

Para a realização da etapa dois, foram agendadas entrevistas com os engenheiros responsáveis por gerenciar os canteiros de obras para obtenção dos dados inerentes as obras em estudo, e para aplicação do questionário elaborado com base na compilação de práticas lean apresentadas por Carvalho (2013) relacionadas aos onze princípios de Koskela (1992), com o intuito de analisar o grau de adoção. E na etapa três, foi realizada a coleta por meio de observações diretas nos canteiros de obras e registro fotográfico com o objetivo de descrever a atual situação do canteiro. É importante ressaltar que não houve necessidade de refazer o planejamento do projeto, e o cronograma previsto foi cumprido. Esse possível replanejamento estava previsto no método de pesquisa abordado na figura 3.1 que trata das etapas de pesquisa, o qual é representado pela linha tracejada.

Após o momento de condução dos estudos de caso (coleta de dados nas obras e consolidação de todas as informações obtidas a partir das entrevistas e observações diretas realizadas nos canteiros de obras), foi redigido um relatório para cada caso individual, visando demonstrar a situação de cada canteiro e permitir a análise do grau de adoção dos princípios do $L C$. Ressalta-se que o pesquisador frequentou as dependências das empresas em um período de quatro meses, com uma visita a cada semana.

\subsection{Análise de dados}

$\mathrm{Na}$ fase de análise de dados, o trabalho foi analisado e concluído. A referida análise foi constituída de duas etapas: elaborar as conclusões referentes aos casos, referente aos pontos em comum inerentes à aplicação das práticas do $L C$ e a elaboração do relatório de casos cruzados, que é 
uma técnica analítica que, segundo Yin (2010), aplica-se especificamente à análise de casos múltiplos, e que aborda de forma detalhada as relações entre os dois casos estudados a fim de revelar as particularidades e aspectos comuns quanto ao grau de adoção dos princípios do $L C$ nos referidos canteiros.

\section{Resultados e discussões}

Nesta seção foram relatados os resultados e discussões obtidos a partir dos estudos de casos múltiplos, e inclui o relatório de casos cruzados e o desempenho global dos canteiros inerente à aplicação dos princípios do $L C$, com os respetivos percentuais de desempenho por princípio.

\subsection{Relatório de Casos Cruzados}

O relatório de casos cruzados abordou a análise das práticas lean observadas e o grau de adoção de cada princípio proposto por Koskela (1992) nos canteiros de obras, quanto aos quatro intervalos de classificação propostos por Lucato et al. (2006) como citado em Carvalho (2008), conforme tópicos a seguir:

\subsubsection{Reduzir as atividades que não agregam valor}

No que se refere ao primeiro princípio proposto por Koskela (1992) - redução das atividades que não agregam valor (ou seja, atividades que geram desperdícios), foi constatado que nos dois canteiros existem incentivos para a redução de desperdícios na obra. No entanto, verificou-se certa quantidade de material em torno dos canteiros e entre os pavimentos (canteiro A), tais como: madeira, telhas, aços, estruturas de ferro, carrinhos de mão, etc., conforme mostrado na figura 2. Conforme Salem et al. (2014) sugerem, os trabalhadores, além de serem encorajados, devem manter o local de trabalho limpo e organizado toda vez que determinada atividade for concluída. 
Figura 2

(a) Desperdícios gerados pela obra; (b) Desperdícios entre os pavimentos; (c) Estruturas de Ferro desperdiçadas

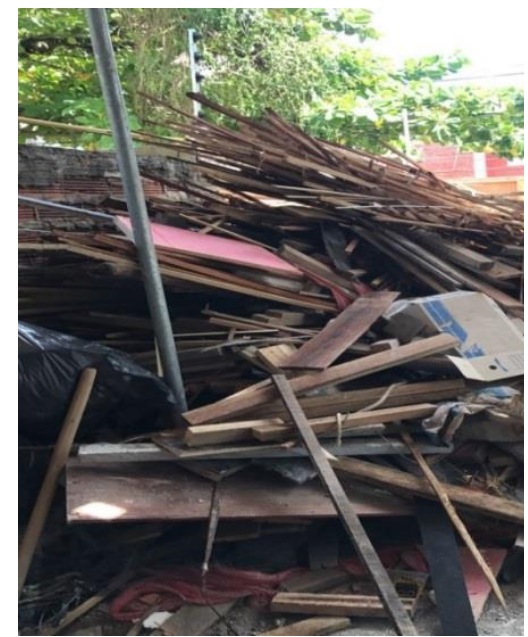

(a)

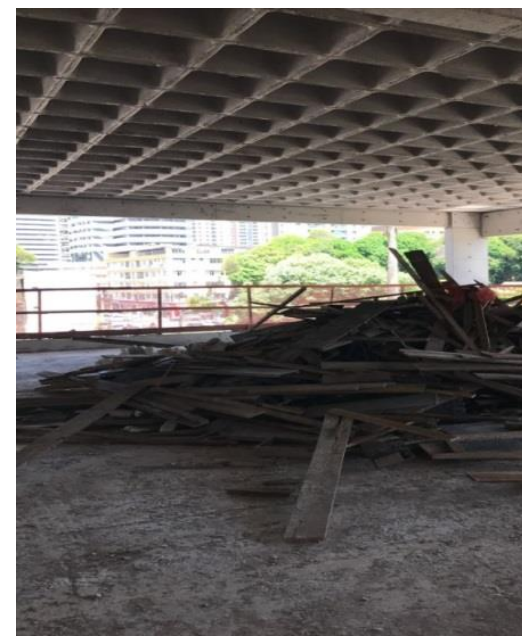

(b)

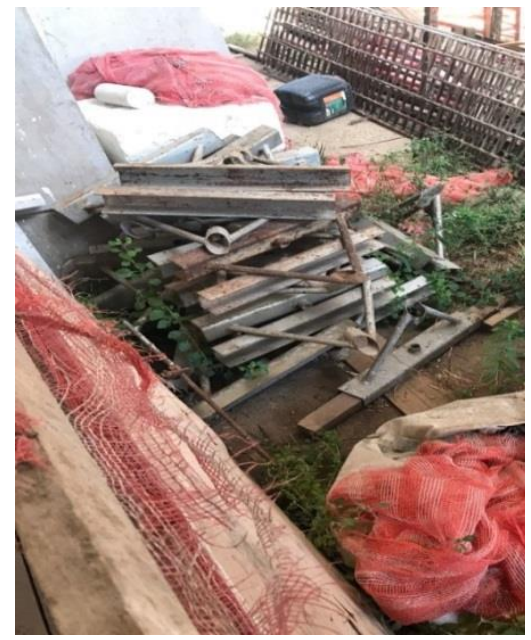

(c)

Fonte: Autor (2019)

Isso sinaliza, conforme Shang e Pheng (2014), o indício de várias barreiras de implementação das práticas do $L C$, tais como: treinamento insuficiente, falta de apoio da alta administração, tolerância dos funcionários a locais de trabalho desorganizados e ausência de uma cultura enxuta nos canteiros.

Embora a redução de desperdícios tenha sido planejada na fase de concepção do projeto em ambos os canteiros, as medidas adotadas ainda estão muito aquém da ideal para alcançar uma redução significativa de tais desperdícios. Isto é um fator que deve ser cuidadosamente considerado no gerenciamento de projetos (Ballard \& Koskela, 2008 como citado por Vivan \& Paliari, 2012).

Nos dois canteiros, não foi feito o planejamento do fluxo de materiais para eliminação ou minimização de estoques e transportes ineficientes de recursos, o que pode ocasionar perdas causadas por layout inadequado (Agyekum, Ayarkwa \& Adjei-kumi, 2013), o que representa um indício de conhecimento insuficiente de lean, habilidades insuficientes de gerenciamento, ausência de uma cultura enxuta, barreiras determinantes para implementação eficaz das práticas do LC (Shang \& Pheng, 2014).

Há utilização de pré-moldados apenas no canteiro A, o que representa um indicativo da ausência de uma cultura enxuta no canteiro B, conforme sugerem (Shang \& Pheng, 2014).

Tal prática também pode ser considerada um incentivo para redução de desperdícios, pois é fundamental para diminuição do tempo de obra, da necessidade de funcionários, dos custos do empreendimento, do volume de resíduos da construção produzidos, e aumento da produtividade e competitividade das empresas (Castro, 2013). 
A segurança nos dois canteiros de obra é garantida, ou no mínimo incentivada, por meio da exigência do uso de equipamentos de proteção individual (EPI), tais como: luvas, botas, óculos, capacetes, etc., e adoção de equipamentos de proteção coletiva (EPC), como: redes de proteção e aparadores em torno da obra, para proteção dos colaboradores contra queda e projeção de materiais provenientes dos processos construtivos, o que é natural do ideal da construção lean para a eliminação de desperdícios (Sacks, Rozenfeld, \& Rozenfeld, 2005). No entanto, foram encontrados avisos de segurança somente pelo canteiro A, o que indica habilidades insuficientes de gerenciamento, ausência de uma cultura enxuta, falta de apoio da alta administração e barreiras significativas para implementação das práticas do LC (Shang \& Pheng, 2014).

São utilizadas ferramentas de TI para integrar os agentes da cadeia e para detectar e corrigir erros antes da produção apenas no canteiro de obra A, ao indicar conhecimento insuficiente de lean por parte do canteiro B, outro impeditivo para adoção das práticas do $L C$. Tais ferramentas são cruciais à redução de desperdícios (Ballard et al., 2003; Green \& May, 2005), e fundamentais para integração entre os agentes da cadeia de suprimentos e suas tarefas, além do aumento da chance de sucesso em relação a custos e ao cronograma (O'connor \& Yang, 2004; Woksepp \& Olofsson, 2008 como citado em Eriksson, 2010).

É importante ressaltar que o planejamento do fluxo de materiais por meio do layout, facilitaria a atingir o princípio de aumentar a flexibilidade das saídas, pois tornaria os set-ups mais rápidos, e permitiria redução das atividades que não agregam valor; além disso, há uma redução dos tempos de ciclo dos processos, e, consequentemente um aumento do valor para o cliente, pois os processos passam a ser executados de forma mais eficiente e eficaz.

Assim, o canteiro A obteve um percentual de desempenho para este princípio de 54,17\%, situado no intervalo entre 50\% a 75\%, que indica a aplicação do princípio, porém há oportunidades para desenvolvê-lo. O canteiro B obteve um percentual de 41,67\%, localizado no intervalo entre $25 \%$ a 50\%, o qual significa que há incidência de aplicação do princípio, porém de maneira inconsciente.

\subsubsection{Aumentar o valor para o cliente}

Quanto ao segundo princípio do $L C$, que estabelece aumentar o valor para o cliente, foi verificado que os dois canteiros sugerem o valor para o cliente em uma perspectiva de "vida inteira" do produto, vital para a maximização do valor do LC (Mao \& Zhang, 2008; Jorgensen \& Emmitt, 2008; Winch, 2006 como citado em Eriksson, 2010). Jorgensen e Emmitt (2008) reforçam que a filosofia lean somente há sentido na construção civil se o valor e desperdícios são definidos em relação a uma perspectiva da "vida inteira" da edificação. 
Há identificação clara das necessidades do cliente desde o projeto nos dois canteiros (Freire \& Alarcón, 2002; Styhre et al., 2004; como citado em Eriksson, 2010). Ocorre mudança de métodos construtivos quando necessário; manutenção antes da entrega e os dois projetos estão sendo executados com os prazos planejados (Oliveira, Lima, \& Meira, 2007). Entretanto, não são realizados questionários de satisfação durante a entrega e pós-ocupação, nem pesquisas de mercado com compradores potenciais, conforme sugerem (Oliveira, Lima, \& Meira, 2007), o qual sinaliza a falta de uma filosofia lean de longo prazo direcionada à satisfação dos clientes, o que se caracteriza como uma barreira determinante para implementação das práticas do LC (Shang \& Pheng, 2014).

Dessa maneira, os dois canteiros obtiveram um percentual de desempenho para este princípio de $66,67 \%$, que está localizado no intervalo entre $50 \%$ a $75 \%$, o qual indica que o princípio está aplicado, mas há oportunidades de desenvolvimento.

\subsubsection{Reduzir a variabilidade}

Em relação ao terceiro princípio - reduzir a variabilidade- foi verificado que, apesar de algumas atividades serem padronizadas nos dois canteiros de obra, não são documentadas e sistematizadas e, consequentemente, os processos construtivos estão sujeitos a variações, sendo um indício da ausência de uma cultura enxuta nos dois canteiros, uma das barreiras mais significativas na implementação das práticas do LC (Shang \& Pheng, 2014).

Embora sejam adotadas práticas de identificação e eliminação de problemas no processo nos dois canteiros para verificação e solução de alguma inconformidade existente, não é realizada nenhuma prática padrão de medição, o que contribui para o aumento de perdas por especificações erradas (Agyekum, Ayarkwa \& Adjei-Kumi, 2013).

Ademais, apenas no canteiro de obra A são utilizadas ferramentas que auxiliam na redução da variabilidade, como dispositivos Poka-Yokes (dispositivos à prova de erro), gabaritos e moldes. Segundo Koskela (1992) abordagens como a utilização de Poka-Yokes, padronização de atividades (por meio da implementação de procedimentos padronizados) e medição, além da identificação da causa de falhas e eliminação de problemas no processo são fundamentais para a redução da variabilidade nos processos, e redução de perdas por retrabalho (Nery, Zattar, \& Oliveira, 2017). Isso sinaliza a ocorrência de uma das barreiras para implementação das práticas do $L C$, o conhecimento insuficiente de lean (Shang \& Pheng, 2014).

Dessa forma, o canteiro A obteve um percentual de desempenho neste princípio de 55,56\%, localizado dentro do intervalo entre $50 \%$ a $75 \%$, qual mostra que o princípio está aplicado, mas há oportunidades de desenvolvimento. Enquanto o canteiro B obteve um percentual de $44,44 \%$, está 
situado no intervalo entre 25\% a 50\%, o que indica que há incidência de aplicação do princípio, porém evidencia oportunidades de desenvolvimento.

\subsubsection{Reduzir os tempos de ciclos}

Com relação ao quarto princípio do $L C$ - reduzir os tempos de ciclo - foi constatado que a ordem dos processos é alterada conforme necessidade nos canteiros A e B, assim ocorre a busca por sincronização e suavização dos fluxos na obra. Porém, as atividades que agregam valor não são isoladas das atividades de suporte nos canteiros, conforme sugere Koskela (1992), o que denota uma ausência de uma cultura enxuta nos dois canteiros, habilidades insuficientes de gerenciamentos e dois impeditivos para implementação das práticas do LC (Shang \& Pheng, 2014).

São feitas fiscalizações diárias nos dois canteiros de obra (Oliveira, Lima, \& Meira, 2007); cumprimento e melhoramento da programação de tarefas (Ballard et al., 2003) e alterações no layout de canteiro para otimização de espaço e circulação (Koskela, 1992; Oliveira, Lima, \& Meira, 2007). No entanto, não são realizados o gerenciamento da inter-relação entre atividades com ênfase na interrelação de tarefas em vez de atividades específicas (Green \& May, 2005; Pheng \& Fang, 2005; Winch, 2006 Jorgensen \& Emmitt, 2008 como citado em Eriksson, 2010), outro indicador de habilidades insuficientes de gerenciamento (Shang \& Pheng, 2014).

Dessa maneira, tanto o canteiro A quanto o B obtiveram um percentual de desempenho para este princípio de $47,62 \%$, encontrado dentro do intervalo entre $25 \%$ a $50 \%$, que demonstra incidência de aplicação do princípio, mas de maneira involuntária.

\subsubsection{Simplificações do processo}

No tocante ao quinto princípio do $L C$ - simplificações dos processos- não são feitas a utilização de pré-fabricados ou outras técnicas que permitam a redução do número de passos nos dois canteiros, conforme sugere Koskela (1992), com exceção da utilização de pré-moldados pelo canteiro A. O uso de sistemas construtivos pré-fabricados traz várias vantagens que contribuem para o menor tempo de duração da obra e para redução da perda de material, evitando perdas por motivo de método de construção inapropriado (Deffense \& Cachadinha, 2011; Zhai, Zhong, \& Huang, 2015)

Deve-se ressaltar que solicitar o pedido ao fornecedor de aço já cortado e dobrado para os elementos estruturais é outro modo de minimizar o número de etapas e contribuir para redução de perdas de material, pois elimina algumas etapas no processo de armação, e a simplificação dos processos contribui tanto para a redução dos tempos de ciclos, quanto para aumento da transparência dos processos (Koskela, 1992). 
Desse modo, o canteiro A obteve um percentual de desempenho para este princípio de 16,67\%, e o canteiro B um percentual $0 \%$, situados dentro do intervalo entre $0 \%$ a $25 \%$, que mostra que o princípio não está presente nos canteiros.

\subsubsection{Aumentar a flexibilidade das saídas}

Em relação ao sexto princípio do $L C$, - aumentar a flexibilidade das saídas - foi constatado que nos dois canteiros há a utilização de equipamentos flexíveis, mas no canteiro A existem mais, o que apresenta um uso limitado de técnicas de construção no canteiro de obra B, uma das barreiras para adoção das práticas do LC (Shang \& Pheng, 2014). Nos dois canteiros não existem operários multifuncionais, e os set-ups do canteiro A são discretamente mais velozes que os do canteiro $B$. Segundo Picchi (2003), tais práticas são fundamentais porque tornam os processos mais flexíveis.

Há planos de trabalho semanais para o controle do fluxo de trabalho e desenvolvimento de planos de ação com as readequações necessárias apenas no canteiro A, sendo o indicador de habilidades insuficientes de gerenciamento no canteiro de obra B, um dos impedimentos para implementação das práticas do LC (Shang \& Pheng, 2014). Essa prática permite a identificação de tarefas que não foram cumpridas no prazo determinado para que suas respectivas causas sejam reconhecidas e, dessa forma, um plano de ação seja desenvolvido para se adequar à mudança (Eriksson, 2010).

Dessa forma, o canteiro A obteve um percentual de desempenho para este princípio de 50\%, e o canteiro B de $25 \%$, percentuais que estão dentro do intervalo entre $25 \%$ a $50 \%$, que indica que nos dois canteiros há incidência de aplicação do princípio, porém de maneira involuntária.

\subsubsection{Aumentar a transparência dos processos}

No que concerne ao sétimo princípio do LC - aumentar a transparência do processo - foi constatado que nos canteiros A e B é realizada a manutenção da limpeza e da organização do ambiente do trabalho pelos operários diariamente. No entanto, ambos contêm materiais distribuídos por todo o canteiro. Não há controles visuais, indo de encontro com que Koskela (1992) sugere, pois tal prática favorece o aumento da transparência nos processos. Isso é um fator indicativo de conhecimento insuficiente de lean e é uma das principais barreiras para adoção das práticas do LC (Shang \& Pheng, 2014). Além disso, são explícitos, apenas no canteiro A, todos os funcionários, os marcos (milestones) estabelecidos no cronograma para envolvimento desses na execução, com demonstração de ausência de uma cultura enxuta no canteiro de obra B, o qual constitui uma das principais barreiras para implementação das práticas do $L C$. Essa prática é importante para que todos os participantes do projeto se sintam mais envolvidos na execução (Sacks et al., 2010). 
Dessa maneira, no canteiro A, foi obtido um percentual de desempenho para este princípio de $55,56 \%$, encontrado dentro do intervalo entre $50 \%$ a $75 \%$, o que indica que o princípio está aplicado, mas há oportunidades de desenvolvimento. E no canteiro B, foi obtido um percentual de 33,33\%, localizado no intervalo entre $25 \%$ a $50 \%$, que revela incidência de aplicação do princípio, contudo de maneira involuntária.

\subsubsection{Focar no planejamento e controle do processo completo}

A respeito do oitavo princípio do $L C$, - focar no planejamento e controle do processo completo - foi verificado que, nos canteiros A e B, são realizados os seguintes procedimentos: acompanhamento do percentual de tarefas concluídas em relação ao cronograma (Eriksson, 2010), a identificação das causas das falhas e tomada de medidas para prevenir reincidência de erros na obra (Eriksson, 2010); o planejamento da produção visando à manutenção do ritmo de trabalho em vez de picos de produtividade em determinadas atividades (Conte \& Gransberg, 2001); o controle dos custos e o consumo de matéria prima e mão de obra em cada tarefa de acordo com a demanda definida no planejamento da produção (Conte \& Gransberg, 2001); assim como é feito nos canteiros o uso de erros de planejamento como fonte de aprendizado (Conte \& Gransberg, 2001).

Entretanto, observou-se que apenas no canteiro A é realizado o estabelecimento de marcos (milestones) necessário para aumentar o foco no cronograma (Sacks et al., 2010), e o estabelecimento de planos semanais para controle do fluxo de trabalho, fundamental caso seja necessário realizar um ajuste rápido no planejamento da produção (Eriksson, 2010), sendo um indicativo da ausência de uma cultura enxuta no canteiro de obra B, uma das barreiras mais significativas para implementação das práticas do LC (Shang \& Pheng, 2014).

Ademais, verificou-se que a ferramenta Last Planner não é utilizada nos dois canteiros, sendo um elemento-chave possível para melhorar o planejamento e controle eficiente da produção (Campos \& Azevedo, 2016; Vargas \& Formoso, 2019; Fabro et al., 2020), e também é um indício de duas barreiras para implementação das práticas do $L C$, conhecimento insuficiente de lean e habilidades insuficientes de gerenciamento (Shang \& Pheng, 2014).

Desse modo, foi obtido um percentual de desempenho para este princípio de 79,17\% com o canteiro A, encontrado dentro do intervalo entre $75 \%$ a $100 \%$, o qual mostra que o princípio está totalmente presente e resulta em melhorias para a empresa. No caso o canteiro B obteve um percentual de $45,83 \%$, ou seja, dentro do intervalo entre $25 \%$ a 50\%, apontando que há incidência de aplicação do princípio, porém de maneira inconsciente. 


\subsubsection{Melhoria contínua dos processos}

No que tange ao nono princípio do $L C$, - melhoria contínua dos processos, o qual é de suma importância para redução de desperdícios (princípio 1) e para aumentar a eficiência no processo construtivo ao longo do tempo (Green \& May, 2005; (Nery, Zattar, \& Oliveira, 2017), foi verificado que são adotados nos dois canteiros os seguintes elementos: o desenvolvimento de relacionamentos, boa comunicação, integração e coordenação de todas as partes (internas e externas) e em todas as fases, assegurada pelo engenheiro (Elfving et al., 2005; Pheng \& Fang, 2005; Suess, 2005 como citado em Eriksson, 2010). Os colaboradores em tais canteiros são encorajados a desenvolver ideias e soluções de melhorias para problemas que possam aparecer na obra (Pheng \& Fang, 2005; como citado em Eriksson, 2010). E são feitas reuniões periódicas com a equipe da obra (Salem et al., 2014). É importante ressaltar que são realizadas poucas reuniões no canteiro de obra B, sendo um indicativo de habilidades insuficientes de gerenciamento. Segundo Shang e Pheng (2014), as práticas Lean requerem equilíbrio entre habilidades profissionais e habilidades interpessoais de gerenciamento.

Porém, foi verificado que apenas no canteiro de obra A, existem relações de cooperação entre a empresa e fornecedores para a transferência de conhecimentos e para solução conjunta de problemas (Eriksson, 2010); o uso de ferramentas colaborativas com os parceiros, como a delimitação de objetivos comuns, escritórios conjuntos, trabalho em equipe (Green \& May, 2005), redivisão de responsabilidades ao longo da cadeia (Hirota \& Formoso, 2000), e treinamento periódico (Freire \& Alarcón, 2002; Green \& May, 2005), o que indica a ausência de uma cultura enxuta no canteiro de obra B e dos parceiros envolvidos e duas barreiras para implementação das práticas do LC (Shang \& Pheng, 2014). Além disso, nenhum dos canteiros de obra faz uso de indicadores de desempenho, os quais de acordo com Freire e Alarcón (2002) são vitais para determinar se o desempenho está melhorando, sendo um indicativo de habilidades insuficientes de gerenciamento (Shang \& Pheng, 2014)

Dessa forma, o canteiro A obteve um percentual de desempenho 71,43\% para este princípio, localizado dentro do intervalo entre 50\% a 75\%, que aponta que o princípio está aplicado, porém há oportunidades de desenvolvimento. E o canteiro B com percentual correspondente a $28,57 \%$, está situado no intervalo entre $25 \%$ a $75 \%$, que aponta incidência de aplicação do princípio, porém de maneira inconsciente.

\subsubsection{Equilibrar melhorias de fluxo com melhoria na conversão}

Quanto ao décimo princípio do $L C$ - equilibrar melhoria de fluxo com melhoria na conversão - foi observado que apenas o canteiro A faz a gestão do fluxo de informações, materiais e mão de obra na delimitação das responsabilidades (Hirota \& Formoso, 2000) e busca desenvolver as competências gerenciais dos profissionais para promoverem o processo de mudança (Hirota \& Formoso, 2000), 
aspecto de suma importância para o incentivo da adoção e implementação das práticas do $L C$ no canteiro de obras. O fator é um indício da ausência de uma cultura enxuta no canteiro de obras, uma das barreiras mais significativas para adoção das práticas do LC (Shang \& Pheng, 2014).

Assim, o canteiro A obteve um percentual de desempenho para este princípio de 33,33\%, localizado dentro do intervalo de 25\% a 50\%, que aponta que há incidência de aplicação do princípio, porém de maneira inconsciente. E o canteiro B, por não aplicar tais práticas, obteve um percentual de 0\%, que mostra que este princípio não está presente.

\subsubsection{Benchmarking}

E em relação ao último princípio do $L C$, Benchmarking, foi constatado nos canteiros que não é realizada a busca por boas práticas com análise de obras de empresas concorrentes, e obras de outros países, para avaliação das forças, fraquezas, oportunidades e ameaças da organização, o que pode ser um indício de conhecimento insuficiente de Lean. Segundo o Lean Enterprise Institute (LEI) 2007 conforme citado por Shang e Pheng (2014), essa é uma das maiores barreiras para implementação das práticas do $L C$. Logo, os canteiros A e B obtiveram um percentual de desempenho de $0 \%$ para este princípio, que se encontra no intervalo de $0 \%$ a $25 \%$, indicando que este fator não está presente nos canteiros.

Segundo Koskela (1992), ao realizar essa análise, as construtoras poderão incorporar (copiando ou modificando) melhores práticas à empresa, e delinear um nicho de mercado pela combinação das forças existentes da companhia com as melhores práticas externas.

\subsection{Desempenho global dos canteiros}

Conforme resultados obtidos a partir do questionário aplicado aos engenheiros responsáveis pelas obras em estudo, e das observações feitas nos canteiros de obras, foi gerada a tabela 3 que mostra o percentual de desempenho por princípio e o desempenho global em cada canteiro. O canteiro A obteve um desempenho global de $57,52 \%$, sendo classificado com o nível e subnível C - que indica foco em qualidade, porém baixo ou nenhum conhecimento nas práticas do $L C$, confirmando, de acordo com Shang e Pheng (2014), a percepção de algumas barreiras significativas para implementação das práticas lean percebidas nesse canteiro, tais como: conhecimento insuficiente de lean, habilidades insuficientes de gerenciamento e ausência de uma cultura enxuta no canteiro. 
Tabela 3

Índice de Desempenho Global dos Canteiros A e B

\begin{tabular}{|c|c|c|c|c|c|}
\hline \multirow[b]{2}{*}{ Princípios } & \multirow[b]{2}{*}{$\sum$ máx. das respostas } & \multicolumn{2}{|c|}{ Canteiro de Obra A } & \multicolumn{2}{|c|}{ Canteiro de Obra B } \\
\hline & & $\begin{array}{l}\Sigma \text { das } \\
\text { respostas }\end{array}$ & $\begin{array}{c}\% \text { de } \\
\text { desempenho }\end{array}$ & $\begin{array}{l}\sum \text { das } \\
\text { respostas }\end{array}$ & $\begin{array}{c}\% \text { de } \\
\text { desempenho }\end{array}$ \\
\hline $\begin{array}{l}\text { 1- Reduzir as atividades que } \\
\text { não agregam valor }\end{array}$ & 24 & 13 & $54,17 \%$ & 10 & $41,67 \%$ \\
\hline $\begin{array}{l}2 \text {-Aumentar o valor para o } \\
\text { cliente }\end{array}$ & 18 & 12 & $66,67 \%$ & 12 & $66,67 \%$ \\
\hline 3 - Reduzir a variabilidade & 9 & 5 & $55,56 \%$ & 4 & $44,44 \%$ \\
\hline 4 - Reduzir os tempos de ciclo & 21 & 10 & $47,62 \%$ & 10 & $47,62 \%$ \\
\hline 5 - Simplificação dos processos & 6 & 1 & $16,67 \%$ & 0 & $0 \%$ \\
\hline $\begin{array}{l}6 \text { - Aumentar a flexibilidade das } \\
\text { saídas }\end{array}$ & 12 & 6 & $50,00 \%$ & 3 & $25,00 \%$ \\
\hline $\begin{array}{l}7 \text { - Aumentar a transparência } \\
\text { dos processos }\end{array}$ & 9 & 5 & $55,56 \%$ & 3 & $33,33 \%$ \\
\hline $\begin{array}{l}8 \text { - Focar no planejamento e } \\
\text { controle do processo completo }\end{array}$ & 24 & 19 & $79,17 \%$ & 11 & $45,83 \%$ \\
\hline $\begin{array}{l}9 \text { - Melhoria contínua dos } \\
\text { processos }\end{array}$ & 21 & 15 & $71,43 \%$ & 6 & $28,57 \%$ \\
\hline $\begin{array}{l}10 \text { - Equilibrar melhorias de } \\
\text { fluxo com melhoria na } \\
\text { conversão }\end{array}$ & 6 & 2 & $33,33 \%$ & 0 & $0 \%$ \\
\hline 11 - Benchmarking & 3 & 0 & $0 \%$ & 0 & $0 \%$ \\
\hline DESEMPENHO GLOBAL & 153 & 88 & $57,52 \%$ & 59 & $38,56 \%$ \\
\hline
\end{tabular}

Fonte: Autor (2019).

O canteiro de Obra B obteve um desempenho global de 38,56\%, sendo classificado com o nível e subnível $D$ - que indica baixo foco em melhorias e consciência nula sobre as práticas do $L C$, colaborando com uma das principais barreiras de implementação das práticas do $L C$ observadas conforme a análise das práticas lean que consta no relatório de casos cruzados, - a ausência de uma cultura enxuta nesse canteiro (Shang \& Pheng, 2014).

Em ambos foram observados que são adotadas de forma "natural" e "involuntária" algumas práticas isoladas do LC que contemplam quase todos os onze princípios propostos por Koskela (1992) em graus de intensidade distintos. Essa aplicação fragmentada é considerada uma das principais razões para a limitação da extensão de resultados que podem ser obtidos com a implementação de conceitos lean (Rother,1997 como citado em Picchi \& Granja, 2004).

\section{Considerações finais}

O objetivo deste trabalho de analisar o grau de adoção dos princípios do $L C$ em dois canteiros de obras localizados no município de Belém foi alcançado, pois por meio dos resultados obtidos a partir das entrevistas, questionário e observações diretas nos canteiros, foi possível fazer a análise das práticas lean no relatório de casos cruzados e determinar o percentual de desempenho de cada princípio, além 
de obter o desempenho global de aplicação dos princípios do $L C$ nesses canteiros. Dessa forma, podese afirmar que o questionamento sobre o percentual de desempenho de aplicação dos princípios do $L C$ nesses canteiros foi devidamente respondido.

Concluiu-se que, nos canteiros A e B, apesar de ocorrer a aplicação das práticas do $L C$ inerente a quase todos os princípios propostos por Koskela (1992), e de haver uma maior adoção de tais práticas/preocupação com a qualidade no Canteiro A, foi constatado um baixo ou nenhum conhecimento sobre as práticas do $L C$, sobretudo, dos princípios do $L C$. Isso indica a necessidade das construtoras de reduzirem ou eliminarem as barreiras de implementação das práticas do $L C$, como treinamento insuficiente, habilidades insuficientes de gerenciamento e conhecimento insuficiente de lean, por meio da capacitação de seus profissionais visando torná-los aptos a compreender e a implementar tais práticas, pois é evidente que determinados princípios são aplicados de forma não intencional em tais canteiros.

A contribuição científica deste estudo reside na importância de conhecer o grau atual de $L C$ desses canteiros nessa localidade, e servir como subsídio para ampliar as discussões a respeito desse tema. Como sugestão para continuação desse estudo, sugere-se ampliar o número de canteiros avaliados, visando uma maior consistência nos resultados e a obter um parâmetro geral do cenário paraense da construção civil em relação ao grau de adoção dos princípios do $L C$.

\section{Referências}

Agyekum K., Ayarkwa J. and Adjei-kumi T. (2013), Minimizing Materials Wastage in Construction-A Lean Construction Approach, Journal of Engineering and Applied Science, 5(1).

Alarcón, L.F.; SegueL, L. (2002). Developing incentive strategies for implementation of Lean Construction. Proceedings of the Annual Conference of International Group for Lean Construction (IGLC-10), Gramado, RS, Brasil, 12.

Almeida, Eduardo Lavocat Galvão de, \& Picchi, Flávio Augusto. (2018). Relação entre construção enxuta e sustentabilidade. Ambiente Construído, 18(1), 91-109. https://doi.org/10.1590/s1678-86212018000100211

Andrade, M, \& Arrieta, B. (2011). Last planner en subcontrato de empresa constructora. Revista de la construcción, 10(1), 36-52. https://doi.org/10.4067/S0718-915X2011000100005

Angelim, Vanessa Lira, Alves, Thais da Costa Lago, Lima, Mariana Monteiro Xavier de, \& Barros Neto, José de Paula. (2020). Lookahead planning: overview of its application in construction. Ambiente Construído, 20(1), 87-104. Epub December 05, 2019. https://doi.org/10.1590/s1678-86212020000100364

Aziz, R. F. \& Hafez, S. M. (2013). Applying lean thinking in construction and performance improvement. Alexandria Engineering Journal, 52(4): 679-695. 
Ballard G., Decker D. and Mack J. (2008), Lean Construction of California Health Care, Modern Steel Construction, November, California, USA.

Ballard G. (2009), Current Process Benchmark for Target Value Design, Project Production Systems Laboratory, University of California, Berkeley, Republished in leanconstructionjournal.org, 2012.

Bulhões, lamara Rossi, \& Picchi, Flávio Augusto. (2011). Diretrizes para a implementação de fluxo contínuo em obras de edificações. Ambiente Construído, 11(4), 205223. https://doi.org/10.1590/S1678-86212011000400014

CAMPOS, V. R.; AZEVEDO, M. F. (2016). Análise da distribuição de equipes de trabalho na construção civil: estudo de caso. Exacta - EP, São Paulo, 14 (3), 339-351.

Carvalho, Luciana Sousa de. A. (2013). Adoção de Princípios Lean pelo Setor da Construção Civil. Dissertação (Mestrado em Administração), Universidade Federal do Rio de Janeiro, RJ, Brasil.

Conte, A.S; Gransberg, D. Lean Construction: From Theory to Practice. International Transactions, CSC.10, p.CSC.10.1-CSC.10.5, 2001.

Castro, G. Reforma na obra. (2013, maio 17). Valor Econômico. Caderno Empresas. São Paulo, SP, Brasil.

Eriksson, E. (2010). Improving construction supply chain collaboration and perfomance: a lean construction pilot project. Supply Chain Management: An International Journal, 15 (5), 394403.

Dantas Filho, João Bosco Pinheiro, Barros Neto, José de Paula, \& Angelim, Bruno Maciel. (2017). Mapeamento do fluxo de valor de processo de construção virtual baseado em BIM. Ambiente Construído, 17(4), 343-358. https://doi.org/10.1590/s1678-86212017000400201

Deffense, J.; Cachadinha, N. (2011). Lean Production in the Precast Concrete Components' Industry. Proceedings of the Annual Conference of the International Group for Lean Construction, Lima, Peru, 19.

Euphrosino, Camila Augusto, Pimentel, Lia Lorena, Camarini, Gladis, Ortigara, Yuri Vilas Boas, Ruiz, Phelipe Viana, \& Fontanini, Patrícia Stella Pucharelli. (2019). Mapeamento do processo produtivo e construtivo de alvenaria de tijolo de solo-cimento para habitação de interesse social. Matéria (Rio de Janeiro), 24(4), e12523. Epub November 25, 2019.

Fabro, Fabiana, Bulhões, lamara Rossi, Formoso, Carlos Torres, \& Fireman, Marcus Costa Tenório. (2020). Diretrizes para planejar e controlar o processo de montagem de sistemas construtivos pré-fabricados de aço. Ambiente Construído, 20(2), 505-524. Epub May 08, 2020. https://doi.org/10.1590/s1678-86212020000200412

Freire, J.; Alarcón, L. F. Achieving lean design process: Improvement methodology. Journal of construction engineering and management, Chile, 2002.

Gao Shang, Low Sui Pheng, (2014) "Barriers to lean implementation in the construction industry in China", Journal of Technology Management in China, 9 (2), 155-173.

https://doi.org/10.1108/JTMC-12-2013-0043 
Ghosh S, Bhattacharjee S, Bozorgi PP, Ganapathy R. A case study to examine environmental benefits of lean construction. Oslo (Norway); 2014.

Golzarpoor, H.; Gonzalez, V. (2013). A green-Lean simulation model for assessing environmental and production waste in construction. Proceeding of the Annual Conference of International Group for Lean Construction (IGLC), 885-894, Fortaleza, CE, Brasil, 21.

Green, S.; May. (2005). Lean construction: arenas of enactment, models of diffussion, and the meaning of 'leanness'. Building Research \& Information, 33 (6), 498-511.

Hirota, E. H.; Formoso, C.T. (2000). O processo de aprendizagem na transferência dos conceitos e princípios da produção enxuta para a construção. In: ENTAC, 8ㅇ, Salvador, Bahia. 1. 572-579.

Isatto, E. L. et al. (2000). Lean Construction: diretrizes e ferramentas para o controle de perdas na construção civil. Cadernos da Série Construção Civil, 5. SEBRAE: Porto Alegre, RS, Brasil.

Jorgensen, B.; Emmitt, S. (2008). Lost in transition: the transfer of lean manufacturing to construction. Construction and Architectural Management, 15 (4), 383-398.

Koskela, L. (1992) Application of the New Production Philosophy to Construction, Center for Integrated Facility Engineering, Department of Civil Engineering, Stanford University, USA.

Maradzano, I., Dondofema, R.A., \& Matope, S.. (2019). Application of Lean Principles in the South African Construction Industry. South African Journal of Industrial Engineering, 30(3), 210223. https://doi.org/10.7166/30-3-2240

Nery, V. F. S. O., Zattar, I. C., \& Oliveira, V. O. (2017). Aplicação da Filosofia Lean Construction no Processo Produtivo de uma Empresa do Setor de Construção Civil. Exacta - EP, São Paulo, v. 15(4), 77-89.

Oliveira, D.; Lima, M.; Meira, A. (2007). Identificação das ferramentas da lean nas construtoras de João Pessoa. Congresso de Pesquisa e Inovação da Rede Norte Nordeste de Educação Tecnológica, João Pessoa, PB, Brasil, 2.

Pereira, D. \& Cachadinha, N. (201, july), 'Lean Construction in Rehavilitation Works - Suitable Analysis and Contribution for the Degintion of an Application Model' In:, Rooke, J. \& Dave, B., Proceedings of the Annual Conference of International Group for Lean Construction. Lima, Peru, 13-15, 19.

Picchi, F. A.; Granja, A. D. (2004, August). Construction sites: using lean principles to seek broader implementations). Proceedings of the Annual Conference of International Group for Lean Construction. Elsinore. Denmark, 12.

Pheng, L. S. \& Fang, T. H. (2005) 'Modern-day lean construction principles: Some questions on their origin and similarities with Sun Tzu's Art of War'. Management Decision, 43 (4), 523-541.

Pheng, L. S.; Shang, G.; Peter, L. International Journal of Construction Project Management; Hauppauge 8.1 (2016): 3-23.

Sacks R., Rosenfeld Y. and Rozenfeld O. (2005), "Lean Scheduling for Safety: Development of a Timedependent Risk Level Model", Proceedings of the Annual Conference of International Group for Lean Construction, Sydney, Australia, 13. 
Sacks, R., Koskela, L., Dave, B. A. \& Owen, R., 2010. Interaction of lean and building information modeling in construction. Journal of construction engineering and management, 136(9), pp. 968-980.

Salem, O. et al. (2014) Reducing Environmental, Economic, and Social Impacts of Work-Zones by Implementing Lean Construction Techniques Proceedings of the Annual Conference of International Group for Lean Construction, Oslo, 22.

Salgin, B, Arroyo, P, \& Ballard, G. (2016). Explorando la relación entre los métodos de diseño lean y la reducción de residuos de construcción y demolición: tres estudios de caso de proyectos hospitalarios en California. Revista ingeniería de construcción, 31(3), 191-200. https://doi.org/10.4067/S0718-50732016000300005

Saggin, A. B., Valente, C. P., Mourão, C. A. M. A. and Cabral, A. E. B. (2015, July). Comparing Investments in Sustainability with Cost Reduction from Waste due to Lean Construction. Proceedings of the Annual Conference of International Group for Lean Construction. Perth, Australia, 29-31, 223-232).

Tommelein, I.D. (2008, july). Poka Yoke or Quality by Mistake Proofing Design and Construction Systems." In Tzortzopoulos, P. and Kagioglou, M. (Eds.). Proceedings of the Annual Conference of International Group for Lean Construction (IGLC 16), 16-18, Manchester, UK, 16.

Vargas, Fabrício Berger de, \& Formoso, Carlos Torres. (2020). Método para planejamento e controle da produção baseado em zonas de trabalho com o apoio de BIM. Ambiente Construído, 20(1), 129-151. Epub December 05, 2019. https://doi.org/10.1590/s1678-86212020000100366

Zhai, Y.; Zhong, R. Y.; Huang, G. Q. (2015). Towards Operational Hedging For Logistics Uncertainty Management in Prefabrication Construction. IFAC-PapersOnLine, 48(3), 1128-1133, 2015.

Vivan, André Luiz, \& Paliari, José Carlos. (2012). Design for Assembly aplicado ao projeto de habitações em Light Steel Frame. Ambiente Construído, 12(4), 101-115. https://doi.org/10.1590/S167886212012000400008

Yin, R. K. (2010). Estudo de caso: planejamento e métodos. (4a ed.). Porto Alegre: Bookman. 
Apêndice

Quadro 1

Relação das Práticas lean com os onze princípios do LC

\begin{tabular}{|c|c|}
\hline Princípios & Práticas Lean \\
\hline $\begin{array}{l}\text { 1- Reduzir as } \\
\text { atividades que não } \\
\text { agregam valor }\end{array}$ & $\begin{array}{l}\text { - Planejamento do fluxo de materiais para eliminação ou minimização de estoques e } \\
\text { transportes ineficientes de recursos (Fearne \& Fowler, 2006; Saurin \& Formoso, 2006; } \\
\text { Salem et al., 2006) } \\
\text { - Segurança dos trabalhadores é garantida na obra (Sacks, Rozenfeld, \& Rozenfeld, 2005) } \\
\text { - Adoção de ferramentas de TI para detectar e corrigir erros antes da produção (Ballard \& } \\
\text { Howell, 2003; Green \& May, 2005) } \\
\text { - Utilização de pré-moldados na obra (Green \& May, 2005; Baldwin et al., 2009) }\end{array}$ \\
\hline $\begin{array}{l}2 \text {-Aumentar o valor } \\
\text { para o cliente }\end{array}$ & $\begin{array}{l}\text { - Pesquisas de mercado com compradores potenciais ou avaliações pós-ocupação de } \\
\text { edificações (Isatto, 2000) }\end{array}$ \\
\hline $\begin{array}{l}3 \text { - Reduzir a } \\
\text { variabilidade }\end{array}$ & $\begin{array}{l}\text { - Utilização de dispositivos Poka-Yokes (dispositivos à prova de erro), como gabaritos e } \\
\text { moldes; Padronização nas atividades e Medição, identificação e eliminação de problemas } \\
\text { no processo (Koskela, 1992; Santos, Powell, \& Formoso, 1999) }\end{array}$ \\
\hline $\begin{array}{l}4 \text { - Reduzir os tempos } \\
\text { de ciclo }\end{array}$ & $\begin{array}{l}\text { - Atividades que agregam valor isolado das atividades de suporte (Koskela, 1992; Santos, } \\
\text { Powell, \& Formoso, 1999) }\end{array}$ \\
\hline $\begin{array}{l}5 \text { - Simplificação dos } \\
\text { processos }\end{array}$ & $\begin{array}{l}\text { - Minimização do número de etapas, partes e ligações através de planejamento (Koskela, } \\
\text { 1992) } \\
\text { - Utilização de pré-fabricados ou outras técnicas que permitam a redução do número de } \\
\text { passos (Green \& May, 2005; Baldwin et al., 2009) }\end{array}$ \\
\hline $\begin{array}{l}6 \text { - Aumentar a } \\
\text { flexibilidade das saídas }\end{array}$ & $\begin{array}{l}\text { - Utilização de equipamentos flexíveis e Operários multifuncionais (Picchi, 2003) } \\
\text { - Planos de trabalho semanais para o controle do fluxo de - trabalho e desenvolvimento de } \\
\text { planos de ação com as readequações necessárias (Eriksson, 2010) }\end{array}$ \\
\hline $\begin{array}{l}7 \text { - Aumentar a } \\
\text { transparência dos } \\
\text { processos }\end{array}$ & $\begin{array}{l}\text { - Manutenção da limpeza e da organização do ambiente de trabalho e Controles visuais na } \\
\text { obra (Santos, Powell, \& Formoso, 1999) }\end{array}$ \\
\hline $\begin{array}{l}8 \text { - Focar no } \\
\text { planejamento e } \\
\text { controle do processo } \\
\text { completo }\end{array}$ & $\begin{array}{l}\text { - Uso da ferramenta Last Planner (Ballard \& Howell, 2003; Jorgensen \& Emmitt, 2008) } \\
\text { - Uso de erros de planejamento como fonte de aprendizado; Controle dos custos e o } \\
\text { consumo de matéria prima e mão de obra em cada tarefa de acordo com a demanda } \\
\text { definida no planejamento da produção (Conte \& Gransberg, 2001) } \\
\text { - Identificação das causas das falhas e tomada de medidas para prevenir reincidências de } \\
\text { erros (Eriksson, 2010) }\end{array}$ \\
\hline $\begin{array}{l}9 \text { - Melhoria contínua } \\
\text { dos processos }\end{array}$ & $\begin{array}{l}\text { - Relações de cooperação entre a empresa e fornecedores trabalhando juntos para } \\
\text { transferência de conhecimentos e para solução conjunta de problemas (Eriksson, 2010) } \\
\text { - uso de ferramentas colaborativas com os parceiros: delimitação de objetivos comuns, } \\
\text { escritórios conjuntos, trabalho em equipe (Green \& May, 2005) } \\
\text { - Desenvolvimento de relacionamentos, boa comunicação, integração e coordenação de } \\
\text { todas as partes (internas e externas) e em todas as fases, assegurada pelo engenheiro } \\
\text { (Elfving et al., 2005; Pheng \& Fang, 2005; Suess, } 2005 \text { como citado em Eriksson, 2010) } \\
\text { - redivisão de responsabilidades ao longo da cadeia (Howell, 1999) } \\
\text {-Treinamento periódico (Freire \& Alarcón, 2002; Green \& May, 2005) } \\
\text { - Uso de indicadores de desempenho (Freire \& Alarcón, 2002) } \\
\text { - Reuniões periódicas com a equipe da obra (Salem et al., 2006) }\end{array}$ \\
\hline $\begin{array}{l}10 \text { - Equilibrar } \\
\text { melhorias de fluxo } \\
\text { com melhoria na } \\
\text { conversão }\end{array}$ & $\begin{array}{l}\text { - Gestão e análise de fluxos de informações, materiais e mão de obra na delimitação das } \\
\text { responsabilidades (Mecca, 1999; Hirota \& Formoso, 2000) } \\
\text { - Desenvolvimento das competências gerenciais dos profissionais para promoção do } \\
\text { processo de mudança (Hirota \& Formoso, 2000) }\end{array}$ \\
\hline 11 - Benchmarking & $\begin{array}{l}\text { - Busca por boas práticas analisando obras de empresas concorrentes ou de outros países } \\
\text { (Koskela, 1992) }\end{array}$ \\
\hline
\end{tabular}

Fonte: Adaptado de Carvalho (2013) 
Quadro 2

Questionário respondido de verificação das Práticas Lean

Princípios Práticas Adotadas

1 - Reduzir as atividades que não agregam valor
Há incentivos para a redução de desperdícios na obra?

Há redução de desperdícios desde a fase de concepção do projeto?

$B$

A

B

Os trabalhadores são encorajados a manterem o local de trabalho limpo e organizado?

Há planejamento do fluxo de materiais para eliminação ou minimização de estoques e transportes ineficientes de recursos?

Há utilização de pré-moldados na obra?

A segurança dos trabalhadores é garantida na obra?

Há adoção de ferramentas de TI para integrar os agentes da cadeia?

Há adoção de ferramentas de TI para detectar e corrigir erros antes da produção?

Você acha que a construtora pensa no valor para o cliente em uma perspectiva de

"vida inteira" do produto?

Há identificação clara das necessidades do cliente desde o projeto?

2 - Aumentar o valor para o cliente

3 - Reduzir a variabilidade

4 - Reduzir os tempos de ciclo

Há realização de questionários de satisfação durante a entrega e pós-ocupação?

Há mudança de métodos construtivos quando necessário?

Há ou haverá manutenção antes da entrega?

O projeto é executado mantendo os prazos planejados?

Há utilização de dispositivos Poka-Yokes (dispositivos à prova de erro), como gabaritos e moldes?

Há padronização nas atividades? Cite algum exemplo?

Há medição, identificação e eliminação de problemas no processo?

Há gerenciamento da interação entre atividades com ênfase na inter-relação de tarefas ao invés de tarefas específicas?

As atividades que agregam valor são isoladas das atividades de suporte?

A ordem dos processos é alterada quando necessário?

Há busca por sincronização e suavização dos fluxos na obra?

Há fiscalização diária na obra?

Há cumprimento e melhoramento da programação de tarefas?

Há ou houve alterações no layout de canteiro para otimização de espaço e circulação?

5 -

São utilizados pré-fabricados ou outras técnicas que permitam a redução do Simplificação número de passos? 
Silva, R. W. (2022, abr./jun.). Grau de adoção dos Princípios do Lean Construction em dois canteiros de obras localizados no munícipio de Belém

\begin{tabular}{|c|c|c|c|c|c|}
\hline \multirow{2}{*}{ Princípios } & \multirow{2}{*}{ Práticas Adotadas } & \multicolumn{2}{|c|}{ Pouco } & \multicolumn{2}{|c|}{ Muito } \\
\hline & & 0 & 1 & 2 & 3 \\
\hline $\begin{array}{l}\text { dos } \\
\text { processos }\end{array}$ & $\begin{array}{l}\text { Há ou houve minimização do número de etapas, partes e ligações através de } \\
\text { planejamento? }\end{array}$ & $\begin{array}{l}\text { A } \\
B\end{array}$ & & & \\
\hline \multirow{4}{*}{$\begin{array}{l}6 \text { - Aumentar } \\
\text { a } \\
\text { flexibilidade } \\
\text { das saídas }\end{array}$} & $\begin{array}{l}\text { Você considera os set-ups (tempo decorrido para a troca de uma ferramenta, } \\
\text { programa ou equipamento de um processo em execução até a inicialização do } \\
\text { próximo processo) rápidos? }\end{array}$ & & & $\begin{array}{l}\text { A } \\
B\end{array}$ & \\
\hline & Há utilização de equipamentos flexíveis? & & B & A & \\
\hline & Há operários multifuncionais? & $\begin{array}{l}\text { A } \\
B\end{array}$ & & & \\
\hline & $\begin{array}{l}\text { Há planos de trabalho semanais para o controle do fluxo de trabalho e } \\
\text { desenvolvimento de planos de ação com as readequações necessárias? }\end{array}$ & B & & A & \\
\hline \multirow{3}{*}{$\begin{array}{l}7 \text { - Aumentar } \\
\text { a } \\
\text { transparênci } \\
\text { a dos } \\
\text { processos }\end{array}$} & $\begin{array}{l}\text { É explícito a todos os funcionários os marcos (milestones) estabelecidos no } \\
\text { cronograma para envolvimento destes na execução? }\end{array}$ & B & & A & \\
\hline & Há manutenção da limpeza e da organização do ambiente de trabalho? & & & & $\begin{array}{l}\text { A } \\
B\end{array}$ \\
\hline & Há controles visuais na obra? & $\begin{array}{l}\text { A } \\
B\end{array}$ & & & \\
\hline \multirow{8}{*}{$\begin{array}{l}8 \text { - Focar no } \\
\text { planejament } \\
\text { o e controle } \\
\text { do processo } \\
\text { completo }\end{array}$} & Há o uso da ferramenta Last Planner? & $\begin{array}{l}\text { A } \\
B\end{array}$ & & & \\
\hline & $\begin{array}{l}\text { Há acompanhamento do percentual de tarefas concluídas em relação ao } \\
\text { cronograma? }\end{array}$ & & & & $\begin{array}{l}\text { A } \\
\text { B }\end{array}$ \\
\hline & $\begin{array}{l}\text { Há identificação das causas das falhas e tomada de medidas para prevenir } \\
\text { reincidências de erros? }\end{array}$ & & & $\begin{array}{l}\text { A } \\
B\end{array}$ & \\
\hline & Há planos semanais para controle do fluxo de trabalho? & B & & & A \\
\hline & Há o estabelecimento de marcos no projeto? & B & & & A \\
\hline & $\begin{array}{l}\text { Há planejamento da produção visando à manutenção do ritmo de trabalho ao invés } \\
\text { de picos de produtividade em determinadas atividades? }\end{array}$ & & B & A & \\
\hline & $\begin{array}{l}\text { Há controle dos custos e o consumo de matéria prima e mão de obra em cada } \\
\text { tarefa de acordo com a demanda definida no planejamento da } \\
\text { produção? }\end{array}$ & & & B & A \\
\hline & Há uso de erros de planejamento como fonte de aprendizado? & & & & $\begin{array}{l}\text { A } \\
B\end{array}$ \\
\hline \multirow{8}{*}{$\begin{array}{l}9 \text { - Melhoria } \\
\text { contínua dos } \\
\text { processos }\end{array}$} & $\begin{array}{l}\text { Há o desenvolvimento de relacionamentos, boa comunicação, integração e } \\
\text { coordenação de todas as partes (internas e externas) e em todas as fases, } \\
\text { assegurada pelo engenheiro? }\end{array}$ & & & & $\begin{array}{l}\text { A } \\
B\end{array}$ \\
\hline & $\begin{array}{l}\text { Há relações de cooperação entre a empresa e fornecedores trabalhando juntos } \\
\text { para transferência de conhecimentos e para solução conjunta de problemas? }\end{array}$ & & & A & \\
\hline & $\begin{array}{l}\text { Há o uso de ferramentas colaborativas com os parceiros: delimitação de objetivos } \\
\text { comuns, escritórios conjuntos, trabalho em equipe? }\end{array}$ & B & A & & \\
\hline & Há ou houve redivisão de responsabilidades ao longo da cadeia? & B & A & & \\
\hline & $\begin{array}{l}\text { Os funcionários são encorajados a desenvolver ideias e soluções de melhorias para } \\
\text { problemas de campo? }\end{array}$ & & & B & A \\
\hline & Há reuniões periódicas da equipe? & & B & & A \\
\hline & Há treinamento periodicamente? & B & & A & \\
\hline & Há o uso de indicadores de desempenho? & $\begin{array}{l}\text { A } \\
B\end{array}$ & & & \\
\hline $\begin{array}{l}10 \text { - } \\
\text { Equilibrar } \\
\text { melhorias de }\end{array}$ & $\begin{array}{l}\text { Há gestão e análise de fluxos de informações, materiais e mão de obra na } \\
\text { delimitação das responsabilidades? }\end{array}$ & B & A & & \\
\hline
\end{tabular}




\begin{tabular}{l|l|l|l|l|}
\hline Princípios & Práticas Adotadas & Pouco & Muito \\
\hline $\begin{array}{l}\text { fluxo com } \\
\text { melhoria na } \\
\text { conversão }\end{array}$ & $\begin{array}{l}\text { Há o desenvolvimento das competências gerenciais dos profissionais para } \\
\text { promoção do processo de mudança? }\end{array}$ & 0 & 1 & 2 \\
\hline $\begin{array}{l}11- \\
\text { Benchmarkin } \\
\text { g }\end{array}$ & $\begin{array}{l}\text { Existe uma busca por boas práticas analisando obras de empresas concorrentes ou } \\
\text { de outros países? }\end{array}$ & A & & \\
\hline
\end{tabular}

\section{Protocolo do estudo de caso}

\section{Visão geral do estudo de caso}

O objetivo deste trabalho é analisar o grau de adoção dos princípios do Lean Construction por meio de um estudo de casos múltiplos em dois canteiros de obras localizados no munícipio de Belém, mediante a verificação das práticas lean inerente aos onze princípios do LC criados por Koskela (1992), e responder o seguinte questionamento, qual o grau de adoção dos princípios nesses canteiros?

Dessa forma, para responder a questão de estudo proposta, foi feito um estudo de caso múltiplo em um canteiro de obra de uma empresa construtora que possui as certificações de qualidade ISO 9001:2008 e PBQP-H nível A, na condição de que essa adota às práticas do $L C$, o qual foi chamado de canteiro de obra A, e em uma obra de uma empresa que não possui nenhuma certificação considerando que essa não adota tais práticas em suas obras, chamada de canteiro de obra B, com intuito de comparálas quanto ao grau de adoção dos princípios do Lean Construction. Importante ressaltar também que, para seleção dos casos foi considerado empresas construtoras que tem como atividade principal a construção de edificações verticais (públicas, residenciais ou comerciais).

Portanto, este protocolo descreve os procedimentos necessários para a condução do estudo de caso, com o propósito de aumentar a confiabilidade da pesquisa. Vale ressaltar que todas as informações coletadas serão mantidas em sigilo, e não serão divulgados os nomes das pessoas, assim como, a razão social das empresas entrevistadas. Após a finalização do trabalho será fornecida uma cópia da mesma para cada empresa participante da pesquisa.

\section{Procedimentos de campo}

O procedimento de campo deste estudo inclui: o plano de coleta de dados e a preparação para realização das visitas, e deverão ocorrer em três etapas.

Plano de Coleta de dados

$\mathrm{Na}$ etapa 1, serão agendadas entrevistas com os executivos das empresas a fim de obter informações sobre a empresa em estudo, tais como: tempo de atuação, segmento, histórico/evolução da empresa, número de funcionários, metros quadrados construídos por ano, número de 
empreendimentos lançados, número de empreendimentos em construção e as certificações e premiações obtidas, conforme roteiro a seguir.

Para a realização da etapa 2, serão agendadas entrevistas com os Engenheiros responsáveis por gerenciar os canteiros de obras. Essas serão agendadas pessoalmente mediante visita a sede da construtora, onde uma data será proposta, de acordo com a disponibilidade da empresa.

Essa coleta de dados será realizada por meio de uma entrevista com o intuito de obter alguns dados referentes a obra em estudo, e questionário elaborado a partir das práticas lean levantadas por Carvalho (2013), baseados na revisão de literatura e nos aspectos relacionados ao objetivo deste estudo, com intuito de analisar o grau de adoção dos princípios do Lean Construction.

E na etapa 3, a coleta será realizada por meio de observações diretas nos canteiros de obras e registro fotográfico se possível com objetivo de descrever a atual situação do canteiro, para isso será solicitada a autorização para o acesso e permanência do pesquisador nas dependências das empresas em um período de quatro meses, com uma visita a cada semana. Bem como, consulta a informações disponíveis em documentos internos das empresas em estudos relacionados ao tema deste trabalho ou em registros de arquivos se houver, para ampliar o entendimento acerca das empresas em estudo.

Importante destacar, que antes da realização das reuniões serão anotadas as informações básicas acerca do entrevistado, tais como: departamento, cargo, função, tempo na função e na empresa. Será solicitada a gravação da entrevista para posterior consulta. Durante as entrevistas, serão anotadas as informações mais relevantes inerentes ao trabalho, buscando sempre estimular os entrevistados a contribuírem livremente com o estudo, e a sua duração poderá ser ajustada conforme a necessidade do entrevistado.

\subsection{Preparação para a realização das entrevistas}

Para a realização das entrevistas será enviado previamente um e-mail aos entrevistados com a descrição geral do estudo com o intuito de situá-los sobre o objetivo deste estudo, e será levado na pesquisa de campo: o roteiro de entrevista e cópias deste roteiro para os entrevistados, quadros impressos para a coleta de dados, gravador, bloco de notas, prancheta, caneta, pen drive e máquina fotográfica se permitido. Importante ressaltar, que o pesquisador estará com vestimenta adequada (bota, calça e camisa/blusa fechadas) para o acesso às instalações.

\section{Questões de estudo de caso}

Essas questões são os lembretes relacionados com a informação que necessita ser coletada e por quê. Por isso, na etapa 1 dos procedimentos de campo serão abordados tópicos relacionados às características do entrevistado e da empresa em estudo com o intuito de conhecê-las, tais como: 


\subsection{Características do entrevistado}

- Departamento

- Cargo

- Função

- Tempo na função

- Tempo na empresa

\subsection{Características da empresa}

- Tempo de atuação

- Número de funcionários (em obra e no setor administrativo - incluindo os próprios e terceirizados)

- Porte da empresa

- Segmento de atuação (ex. edificações públicas, residenciais, comerciais, projetos de engenharia e arquitetura, incorporação e venda de imóveis, etc.)

- Público alvo (classe alta, classe média ou classe baixa)

- Principais clientes (outras construtoras, incorporadoras de edifícios, órgão público, consumidor final, pessoa jurídica do setor privado, etc.)

- Metros quadrados construídos por ano

- Números de empreendimentos lançados

- Tipos dos empreendimentos (alto padrão, padrão normal ou padrão popular)

- Certificações e premiações (ex. ISO 9001, ISO 14001, OHSAS 18001, etc.)

Na etapa 2, serão obtidos alguns dados da obra com o Engenheiro responsável por gerenciar a obra de ambos canteiros, tais como: localização do empreendimento, tipo de empreendimento, quantidade de torres e pavimento se houver, área construída em $\mathrm{m}^{2}$, data de início da obra e a previsão de término, e será aplicado o questionário visando investigar todos os aspectos relacionados às práticas do Lean Construction e os Resíduos da Construção Civil, tais como:

E na etapa 3, serão realizadas as seguintes atividades:

- Observação "in loco" para verificar questões de infraestrutura, organização, fluxos, processos, procedimentos, práticas que são e não são adotadas por meio de observações periódicas nos canteiros, e as possíveis práticas Lean que poderiam ser implementadas para redução dos RCC.

- Coleta de dados a partir de possíveis documentos que possam ser fornecidos pelas empresas relacionados ao tema em estudo para análise complementar. 


\section{Guia para a elaboração da análise de resultados e discussões}

Os resultados obtidos a partir da coleta de dados serão apresentados em um relatório individual de cada caso em formato de texto, que incluirá: os dados da construtora, a caracterização da obra e canteiro em estudo, o resultado da entrevista e questionário realizado com o engenheiro responsável pela obra em estudo; e das observações feitas na obra quanto às práticas adotadas. Posteriormente, será feito um relatório de casos cruzados, àqueles resultados serão resumidos em formato de tabelas, e discutidos minuciosamente, buscando considerar as possíveis explanações e possibilidades rivais encontradas na literatura relacionadas ao tema em estudo, e validar as proposições teóricas definidas.

\section{ROTEIRO DE ENTREVISTAS - ETAPA 1}

\section{1) DADOS DO ENTREVISTADO}

- Qual o seu departamento?

- Qual o seu cargo?

- Qual a sua função?

- Qual o seu tempo na função?

- Qual o seu tempo na empresa?

\section{2) DADOS DA CONSTRUTORA}

- Qual o seu tempo de atuação?

- Qual é o número de funcionários existentes (em obra e no setor administrativo - incluindo os próprios e terceirizados)?

- Qual o seu segmento de atuação (ex. edificações públicas, residenciais, comerciais, projetos de engenharia e arquitetura, incorporação e venda de imóveis, etc)

- Quem é o público alvo (classe alta, classe média ou classe baixa)?

- Quem são os seus principais clientes (outras construtoras, incorporadoras de edifícios, órgão público, consumidor final, pessoa jurídica do setor privado, etc.)?

- Qual a quantidade de metros quadrados construídos por ano?

- Qual o número de empreendimentos lançados?

- Quais os tipos dos empreendimentos (alto padrão, padrão normal ou padrão popular)?

- A empresa possui alguma certificação ou premiação (ex. ISO 9001, ISO 14001, OHSAS 18001, etc.)?

\section{ROTEIRO DE ENTREVISTAS - ETAPA 2}

\section{3) DADOS DA OBRA}

- Qual a localização do empreendimento (endereço)? 
- Qual o tipo de empreendimento?

- Quantas torres e pavimentos se houver? E qual a área construída em $\mathrm{m}^{2}$ ?

- Qual a data de início da obra e a previsão de término?

QUESTIONÁRIO PROPOSTO - ETAPA 2

4) PRÁTICAS LEAN ADOTADAS NO CANTEIRO DE OBRA

Princípios

Práticas Adotadas

1 - Reduzir as atividades que não agregam valor

2 - Aumentar o valor para o cliente

3 - Reduzir a variabilidade

4 - Reduzir os tempos de ciclo

5 - Simplificação dos processos

6 - Aumentar a flexibilidade das saídas
Há incentivos para a redução de desperdícios na obra?

Há redução de desperdícios desde a fase de concepção do projeto? Os trabalhadores são encorajados a manterem o local de trabalho limpo e organizado?

Há planejamento do fluxo de materiais para eliminação ou minimização de estoques e transportes ineficientes de recursos?

Há utilização de pré-moldados na obra?

A segurança dos trabalhadores é garantida na obra?

Há adoção de ferramentas de TI para integrar os agentes da cadeia?

Há adoção de ferramentas de TI para detectar e corrigir erros antes da produção?

Você acha que a construtora pensa no valor para o cliente em uma perspectiva

de "vida inteira" do produto?

Há identificação clara das necessidades do cliente desde o projeto?

Há realização de questionários de satisfação durante a entrega e pós-ocupação?

Há mudança de métodos construtivos quando necessário?

Há ou haverá manutenção antes da entrega?

O projeto é executado mantendo os prazos planejados?

Há utilização de dispositivos Poka-Yokes (dispositivos à prova de erro), como gabaritos e moldes?

Há padronização nas atividades? Cite algum exemplo?

Há medição, identificação e eliminação de problemas no processo?

Há gerenciamento da interação entre atividades com ênfase na inter-relação de tarefas ao invés de tarefas específicas?

As atividades que agregam valor são isoladas das atividades de suporte?

A ordem dos processos é alterada quando necessário?

Há busca por sincronização e suavização dos fluxos na obra?

Há fiscalização diária na obra?

Há cumprimento e melhoramento da programação de tarefas?

Há ou houve alterações no layout de canteiro para otimização de espaço e circulação?

São utilizados pré-fabricados ou outras técnicas que permitam a redução do número de passos?

Há ou houve minimização do número de etapas, partes e ligações através de planejamento?

Você considera os set-ups (tempo decorrido para a troca de uma ferramenta, programa ou equipamento de um processo em execução até a inicialização do próximo processo) rápidos?

Há utilização de equipamentos flexíveis? 


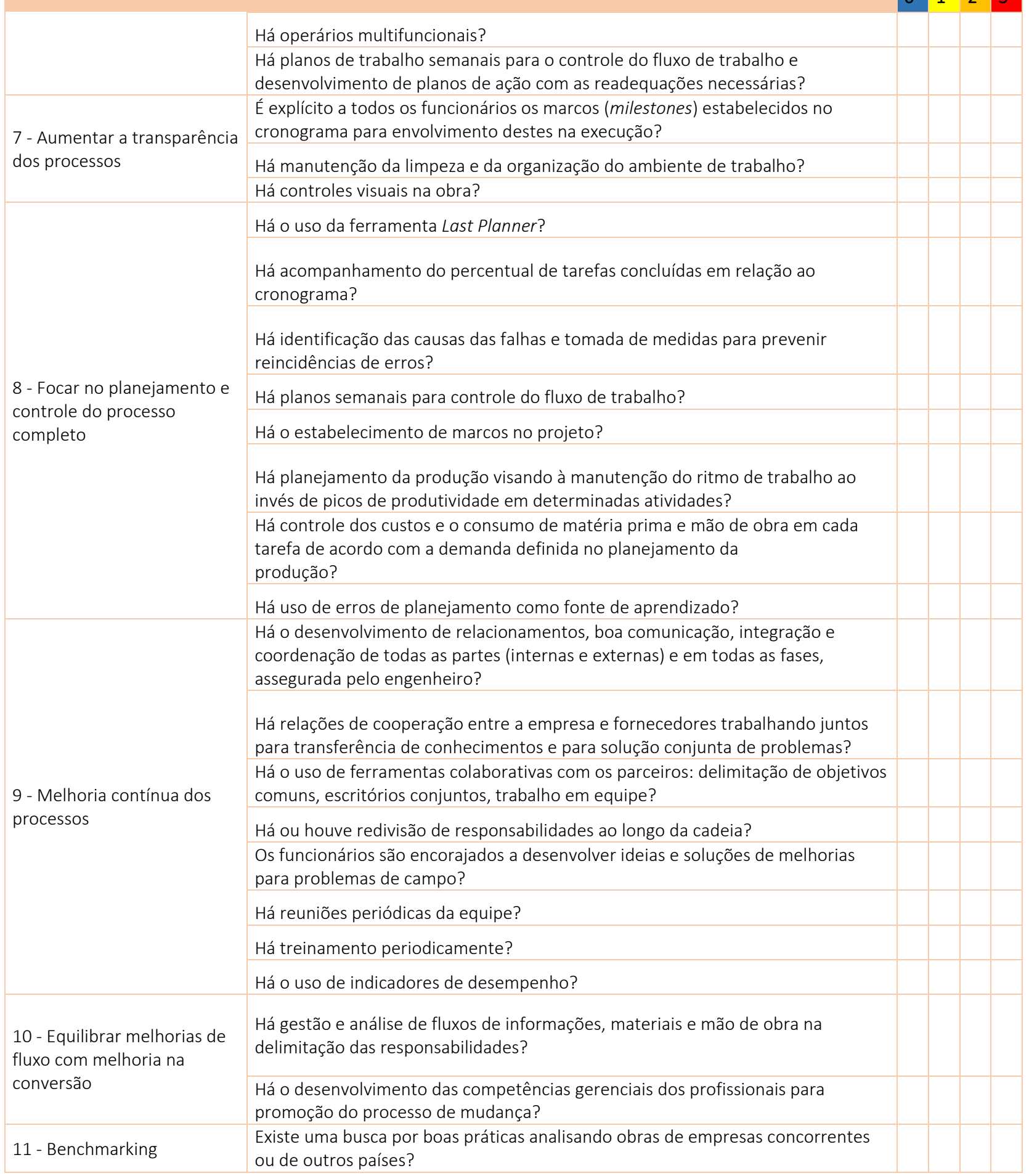

